\title{
Entrepreneurship
}

Jan a Jun $2020-$ v.4 - n.1

ISSN: 2595-4318

This article is also available online at: www.sustenere.co

\section{Buzz do marketing digital: a utilização das mídias sociais como estratégia de interação nas empresas}

O presente estudo tem como objetivo geral analisar quais as maneiras que o buzz do marketing digital traz a seu favor. Em termos específicos que visa, analisar como o buzz marketing digital influência nas estratégias das empresas, verificando e buscando quais os desafios que as empresas enfrentam para divulgar sua marca e identificar quais os benefícios que este tipo de marketing traz para a empresa. Procurando mostrar os melhores meios de comunicação, para o fortalecimento da marca, ganhando mais visibilidade no mercado consumidor. O estudo foi desenvolvido para contribuir no melhor entendimento e familiarizar empresas sobre este assunto que vem tomando grande abrangência neste meio midiático. $\mathrm{O}$ estudo transcorreu-se de fevereiro a novembro de 2019 . 0 estudo e de natureza básica, descritiva, com abordagem qualitativa. Onde o buzz marketing digital é de suma importância para a mesma, pois se trata de uma área da empresa na qual busca trazer e alcançar um público além do esperado através de propagandas, tornando-se um atrativo para as pessoas.

Palavras-chave: Visibilidade; Mercado Consumidor; Buzz Marketing Digital; Benefícios.

\section{Digital marketing buzz: the use of social media as an interaction strategy in companies}

The present study has the general objective of analyzing what the digital marketing buzz brings in its favor. In specific terms, it aims to analyze how digital buzz marketing influences companies' strategies, checking and looking for the challenges that companies face to publicize their brand and identify what benefits this type of marketing brings to the company. Seeking to show the best means of communication, to strengthen the brand, gaining more visibility in the consumer market. The study was developed to contribute to a better understanding and to familiarize companies on this subject, which has been taking a wide range in this media. The study took place from February to November 2019. The study is of a basic, descriptive nature, with a qualitative approach. Where digital buzz marketing is of paramount importance for it, as it is an area of the company in which it seeks to bring and reach an audience beyond what is expected through advertisements, becoming an attraction for people.

Keywords: Visibility; Consumer market; Digital Buzz Marketing; Benefits.

Topic: Marketing e Estratégias Mercadológicas

Reviewed anonymously in the process of blind peer.
Received: $12 / 01 / 2019$

Approved: 25/04/2019

Míriam Rodrigues do Nascimento

Centro Universitário Vale do Salgado, Brasil

http://lattes.cnpq.br/9915049435830796

rodriguesmiriamrodrigues@gmail.com

Hudson Josino Viana

Centro Universitário Vale do Salgado, Brasil

http://lattes.cnpq.br/1413129560129611

hudson.josino@gmail.com

Referencing this:

NASCIMENTO, M. R.; VIANA, H. J.. Buzz do marketing digital: a utilização das mídias sociais como estratégia de interação nas empresas. Entrepreneurship, v.4, n.1, p.17-23, 2020. DOI: http://doi.org/10.6008/CBPC2595-4318.2020.001.0003 


\section{INTRODUÇÃO}

Pode-se dizer que o buzz marketing é de uma forma mais clara, um meio gratuito para divulgação e promoção de uma marca ou produto, empresas ou serviços. Muito comum e usado por consumidores que nos quais fazem a divulgação do produto, Conrado (2016), desta maneira indicando para familiares, amigos e assim por diante. Porém é bem visível que é um dos exemplos de publicidade, sendo que criticada podendo por sua reputação em risco ao recomendar um produto ou serviço.

E o presente estudo tem como objetivo geral analisar as maneiras que as empresas utilizam o buzz do marketing digital a seu favor e como objetivos específicos, analisar como o buzz marketing digital influência nas estratégias das empresas; verificar quais os desafios que as empresas enfrentam para divulgar sua marca; identificar quais os benefícios que este tipo de marketing traz para a empresa. Assim visando quais a são melhores formas e estratégias para o crescimento da organização, utilizadas e desenvolvidas através destes novos sistemas de comunicação que vem crescendo cada vez mais nas mídias sociais.

Quando as pessoas (clientes) fazem a divulgação destes produtos não recebem nada em troca, mas pelo fato de estarem convencidos que o produto é de boa qualidade, sairão divulgando-o assim fazendo o marketing boca-a-boca para parentes, amigos, vizinhos, por sua vez muito conhecido e é praticado há muitos anos pelas pessoas. Deste modo acaba que influenciando outras pessoas ao consumo deste produto ou serviço.

Este tipo de marketing é bastante conhecido como uma influência que está exercendo poder sobre o comportamento do consumidor. Maior parte do marketing boca a boca que existe vem das pessoas, as mesmas consomem e saem fazendo publicidade de determinados produtos ou serviços. Existem também outras formas que o buzz marketing está inserido, são nas páginas de sites e em redes sociais que são mais comuns e mais usadas pelas pessoas, e é um campo onde todos estão inseridos atualmente.

Segundo Conrado (2016) os sites influenciam bastante, todavia é um grande atrativo para as pessoas, ele cita que no site da Avon ele promove uma viralização, e toda mulher que entra no site e ver uma propaganda, naturalmente mexe com os desejos femininos de transformação da mulher. No site sugere que a mulher faça em rede o que ela já faz off-line, pergunte para suas amigas a opinião delas em relação ao corte de cabelo, se ficaria bem. Desta maneira fazendo uma viralização incentivando que outras mulheres entrem no site vindo a ver a propaganda da marca.

Assim, o presente trabalho se justifica pela contribuição que possa vir a dar para as organizações empresariais, bem como lojistas e empreendedores que atuam no mercado para que conheçam e entendam como funciona o buzz marketing, quais as melhores estratégias para utilizarem como recurso de desenvolvimento de sua organização. Tornando-se sua organização, o que pode ser bastante relevante para o comércio. Esta pesquisa salienta a importância para o aprofundamento dos estudos sobre o tema e contribuir no desenvolvimento de empresas, como incentivo para busca de melhorias voltadas a publicidade de seus produtos ou serviços no modo que chame bastante atenção de seus clientes, assim atingindo um público maior aumentando seus lucros e ganhando notoriedade no mercado. $\mathrm{O}$ presente estudo foi realizado 
para evidenciar e analisar quais os impactos que este marketing vem ocasionando de modo negativo ou positivo no ambiente no qual está inserido.

Observou-se que muitas empresas fazem de tudo para chamar atenção de seus clientes, e preferem optar pelo uso das propagandas sejam elas boca-a-boca, via rede social, panfleto, ou rádio que por sua vez é um meio bastante usado nesta região. Porém muitas destas empresas não sabem lidar com estas novas mudanças, que assim ganham novos concorrentes neste novo cenário de atualizações no qual o mercado atual vem passando. Como as empresas utilizam as estratégias de buzz do marketing digital ao seu favor como aperfeiçoamento do seu negócio?.

\section{METODOLOGIA}

Esta pesquisa é do tipo básico, descritiva com abrangência qualitativa. A pesquisa qualitativa é de suma importância para maior entendimento entre o pesquisador e o tema pesquisado. Ela sempre está em consonância com outras fontes que oferecerão base ao assunto abordado, ou seja, ter acesso a ouvintes que tiveram experiências práticas com o tema pesquisado. $O$ caráter descritivo tem como finalidade, retratar as características de determinadas lojas de vestuário de Icó. A abordagem básica se caracteriza por conter informação de pesquisa realizada através de artigos de revistas voltadas ao buzz marketing, não é expressa em números, ou então os números e as conclusões baseadas representam um papel bem menor na análise.

O local de estudo será realizado através de artigos disponíveis na internet, de conhecimento prático do pesquisador, visando quais são as melhores oportunidades para o uso do buzz marketing. Fomentando o mercado que tem o crescimento em passos largos, chamando a atenção de empresas novas na cidade e até multinacionais. Aproveitando o grande movimento da região, que se dará um ponto de partida baseado no mesmo.

Esta pesquisa terá como critério de inclusão para o embasamento de pesquisas na língua portuguesa a fim de viabilizar e mostrar como funciona e se adequa as ferramentas e métodos utilizados através do buzz marketing digital como referência para outros negócios. Serão excluídos da revisão bibliográfica os estudos que não apresentam relação com o objetivo deste estudo, artigos que contrariem a linha de pensamento do mesmo e que não tem relacionamento algum com os objetivos citados no tema.

\section{DISCUSSÃO TEÓRICA}

\section{Marketing}

Existem empresas que produzem produtos certos para seus clientes, pode-se citar de exemplo sham poo clareador para cabelos loiros, e outras, que procuram os clientes certos para seus produtos. E então entra o marketing, que irá realizar sua função em elaborar a melhor estratégia de marketing para que o produto venha crescer no mercado; contudo existem vários tipos de marketing que podem e são utilizados para o crescimento, deste produto.

De acordo com Miranda (2017) marketing de nicho é pensado nos mínimos detalhes, pois quanto 
mais específico for seu público mais vantagem terá no mercado e serão maiores as chances de atender este público. Já marketing sazonal é todo aquele relacionado aos períodos mais festivos de acordo com a cultura da cidade, tais como exemplo: festas juninas, natal, ano novo, dia das mães e outras datas comemorativas, por isso é considerado marketing sazonal. Relata também que marketing de fidelização busca sempre manter sempre o relacionamento com o cliente criando conexões fortes e emocionais com a marca mantendo por mais tempo de maneira intensa.

Para Castro (2010) marketing outbound é o processo de pesquisa ativa para identificar potenciais de clientes que correspondem aos perfis de clientes ideais. E assim como marketing de inbound cria mecanismos para atrair os potenciais dos públicos alvo de forma direta contando que seja um relacionamento duradouro. O marketing de guerrilha é o tipo de marketing que está inserido em ações tradicionais que nem se percebe que está sendo influenciado por algum tipo de marketing. De acordo com Lino (2012) marketing de conteúdo passa a ser a maneira de envolver seu público-alvo e crescer sua rede de clientes e potenciais clientes por meio da elaboração de conteúdo importante e valioso.

Brum (2005) retrata que endomarketing visa o engajamento dos funcionários e o melhor clima organizacional sempre a manter os talentos da empresa. Marketing mobile são as estratégias de marketing que buscam aproveitar as caraterísticas e funcionalidade dos dispositivos móveis, Chuck Martin para melhor comunicação influenciando os clientes e possíveis clientes da sua empresa.

Através destes comportamentos entra o marketing 4.0, no qual é centrado no ser humano, e busca filtrar os atributos de marcas mais semelhantes aos homens e mulheres. Ele é todo voltado para o humano assim cobrindo cada aspecto da jornada do cliente. Diante disso Kotler (2017) diz que se foi do tempo que a meta era ser exclusivo, e que a inclusão se tornou uma nova tendência, agora o mais importante é o reconhecimento da marca.

\section{Comportamento do consumidor}

Segundo Merlo (2014) o comportamento de cada consumidor dependerá de acordo a cultura na qual está inserida (o), pois quando indivíduos ou grupos selecionam, compram, consomem e satisfazem suas necessidades e desejos. Ver-se que sua cultura está influenciando no seu comportamento e refletem sobre os que o motivam ao consumo de cada produto, pelos quais os fatores externos e internos influenciam diretamente em suas decisões.

Podemos dizer que existem fundamentalmente dois tipos de consumidores, os organizacionais e os pessoais. Os consumidores pessoais são aqueles que compram serviços e produtos para o seu uso pessoal, nos quais podemos citar de exemplos: produtos de higiene, alimento, coisas para abranger os conhecimentos, dentre outros. E também os consumidores organizacionais são aqueles e qualquer tipo de empresa ou organização, sendo privadas ou públicas (BANOV, 2017).

De acordo com o pensamento de Banov (2017), no mercado existem grupos de consumidores que compartilham preferências e características parecidas entre si, e ao mesmo tempo, com diferentes ligações partilhadas por outros grupos. Assim existem diversos motivos que influenciam no comportamento de cada 
consumidor que há em volta do mercado.

Há vários fatores que podem influenciar no comportamento dos consumidores, e um dos principais são as tomadas de decisões de compra dos consumidores. Porém Kotler (1998) diz que cada cultura é constituída de subculturas menores nas quais fornecem informações mais especificas para seus membros, influenciando cada vez mais ao consumo de produtos ou serviços.

Segundo Schiffman et al. (2000), as empresas também podem influenciar no comportamento do consumidor, pois é muito importante que haja uma capacitação adequada voltada para o melhor comportamento diante do cliente, sempre buscando o excelente atendimento, deixando-os mais confortáveis e sempre à vontade. Assim influenciará bastante na decisão de compra do mesmo.

\section{Marketing Digital}

Las Cassas (2019), diz que marketing digital é um conjunto de operações eletrônicas que intencionam à transferência de produtos e serviços do produtor para o consumidor. Englobando o uso de e-mails, uso de internet, e prestação de serviços on-line, a principal utilidade do uso dos e-mails são para realização de pedidos para os fornecedores, facilitando o contato do cliente com o fornecedor.

Assim, pode-se dizer que o marketing eletrônico tem uma função muito importante, agregando valores a produção de produtos e serviços. Las Cassas (2019) sempre promovendo a satisfação, criando novas estratégias para persuasão dos consumidores, através da distribuição on-line, com serviços de atendimento e pesquisas de satisfação.

Atualmente com os novos avanços e com o crescimento em grande escala da internet as pessoas estão ligadas o tempo todo em comerciais de televisão, propagandas, jornais, via rede social e, vários outros tipos de comunicação. Mas o marketing ele não deve ser compreendido apenas nesse campo, é muito importante manter a qualidade dos produtos e serviços que estão sendo ofertados, embora as propagandas atuem como função importante para evolução do produto. O marketing deve também buscar se preocupar em alcançar muito mais a qualidade do que a quantidade; ele deve compreender, encantar, servir e corresponder aos desejos dos clientes que são fundamentais para o sucesso do empreendimento, e exige uma gestão desse relacionamento.

No qual onde entra o marketing de relacionamento que é onde desenvolve relacionamentos contínuos e progressivos, sejam eles de maneira direta ou indireta, construir relacionamentos de longo prazo respectivamente satisfatórios com clientes, fornecedores, distribuidores e outros parceiros de marketing, a fim de conquistar e manter negócios através de fortes ligações econômicas, técnicas e sociais entre as partes (KOTLER et al., 2006). Marinho (2008), coloca que:

O marketing de Relacionamento é um conjunto de estratégias que visam ao entendimento e a gestão do relacionamento entre uma empresa e seus clientes, atuais e potenciais, com o objetivo de aumentar a percepção de valor da marca e a rentabilidade da empresa ao longo do tempo.

Assim, obtém-se a iniciativa do consumidor onde o mesmo decide e realizam comparações sobre os produtos e empresas. O mais importante é saber é como os possíveis clientes e os que já existem veem uma 
empresa em relação aos concorrentes. Os consumidores definem uma hierarquia de valores, desejos e necessidades com base em dados empíricos, ou seja, referenciais obtidos através do 'boca-a-boca' e experiências antecedentes com produtos e serviços. Kotler et al. (2006) afirmam que o objetivo é entregar valor a longo prazo para os clientes, e como medida de sucesso obter a satisfação e a conservação de clientes no longo prazo. Isto significa que profissionais deste ramo devem ter um foco maior ao gerenciar seus clientes tanto quanto seus produtos.

\section{Buzz do marketing digital}

Alguns autores definem o buzz marketing como uma ferramenta de publicidade online, porém, mesmo sendo evidente que a maioria das campanhas de buzz marketing são dispersos na Internet, devido à característica do meio, o boca-a-boca ultrapassa a barreira do online fazendo com que as pessoas comentem sobre o assunto em suas redes sociais, estejam elas no ambiente físico ou virtual.

O buzz marketing não busca esconder seu objetivo, mas mostrar seja com tom cômico ou com uma mensagem que incentive a venda de um produto. Com as facilidades criadas pela Internet o buzz marketing ganha forças e meios para atingir um número maior de pessoas com rápida velocidade. As pessoas, usuárias dos produtos e serviços oferecidos repassam a mensagem para sua rede de contatos, sendo que essas pessoas tendem a ter gostos semelhantes. Ou seja, a mensagem é repassada para mais clientes-alvo (MENSHHEIN, 2006).

Percebe-se que as pessoas não procuram o e-mail com muita frequência como antigamente para se pronunciar. Pois as redes sociais permitem, e realizam a abertura de um canal de comunicação direto e rápido. Os clientes podem opinar e checar se estão sendo escutados, seja com respostas nas próprias mídias sociais, seja atendendo uma sugestão de melhorias para um produto. No entanto as empresas que estão ocupando espaço na Internet, mas que não investem em meios de comunicação que criem um diálogo honesto com seu cliente estão confortavelmente no seu modelo antigo.

\section{CONCLUSÕES}

O buzz marketing vem se tornando um grande instrumento no mundo da mídia não só por ele realizar também o boca-a-boca mais por ser um grande diferencial e por atingir um público mais elevado do que o esperado. Sabe-se que com o buzz marketing as empresas ficam sem saber a quantidade aproximada que foi atingida, pois com as mídias tradicionais é possível saber a quantidade de público que foi alcançada através da realização das propagandas de ruas, rádios, TV's e entre outras.

E o este estudo teve como finalidade realizar uma discussão entre o buzz marketing digital e como as empresas fazem para utilização das mídias sociais como estratégia de interação nas empresas. Que podasse perceber que numa realidade de mercado onde existe uma infinidade de marcas e poucas delas possuem realmente um diferencial. As inúmeras comunicações as quais os consumidores são expostos, acabam perdendo a credibilidade. E então os consumidores passam a questionar sobre o que lhes é oferecido e acaba que muitas coisas que são investidas nas mídias tradicionais são em vão. 
Para que se transformem em diferencial utilizam estratégias e fazem de tudo para que o consumidor esteja sempre presente, com a crescente inovação tecnológica pode-se perceber que é um grande atrativo para os clientes, que vem se tornando algo bem criativo e que chama atenção dos mesmos, exemplo: os tutoriais que os blogueiros famosos fazem, esse é um método de propaganda que empresas também adotam e chama muito atenção dos clientes e acaba incentivando-os ao consumo dos produtos que são destacados nos vídeos, e é isto que as pessoas estão vivendo atualmente um nova era de mídia digital, e que vem crescendo cada dia mais. E através dessa estratégia as empresas buscam ser um diferencial.

As empresas estão sempre visando melhorar seu desempenho no mercado, querendo sempre está em alta com olhar para o alcance do melhor desempenho no mercado, e com principal intuito de alavancagem no meio social mostrando quais são as melhores estratégias de crescimento, e incentivando as organizações para que possam ser destaque e inovação. Verificando quais foram os desafios que as empresas enfrentaram para realização da divulgação de sua marca, assim identificando quais foram os benefícios que este tipo de marketing trouxe para as empresas.

\section{REFERÊNCIAS}

BANOV, M. R.. Comportamento do consumidor: vencendo desafios. São Paulo: Cengage, 2017.

BRUM, A. M.. Face a face com o endomarketing. Porto Alegre: L\&PM, 2005.

CASTRO, P. P.. Marketing de Guerrilha: incorporação das mídias radicais no mercado. Florianópolis, 2010.

CONRADO, A. V.. Os 8 Ps do marketing digital: O guia estratégico de marketing digital. 7 ed. São Paulo, 2011.

KOTLER, P.. Administração de marketing: análise, planejamento, implementação e controle. 5 ed. São Paulo: Atlas, 1998.

KOTLER, P.. Marketing 4.0: Recurso eletrônico. Rio de Janeiro: Sextante, 2017.

KOTLER, P.; ARMSTRONG, G.. Introdução ao Marketing. 4 ed. Rio de Janeiro: LTC, 2006.
LAS CASSAS, A. L.. Administração de Marketing. 2 ed. São Paulo: Atlas, 2019.

LINO, S. M. A.. Influência das Redes Sociais no Marketing e na Relação com os Consumidores das Empresas de Cosmética B2C: O Caso Português. Dissertação (Mestrado) Instituto Superior de Contabilidade e Administração de Lisboa, Lisboa, 2012.

MARINHO, P.. O que é Marketing de Relacionamento e a importância da marca. 2009.

MENSHHEIN, R. M.. Buzz marketing. Brasília: Uniceub, 2006.

MERLO, E. M.; CERIBELI, H. B.. Comportamento do consumidor. Rio de Janeiro, 2014.

SCHIFFMAN, L.; KANUK, L. L.. Comportamento do consumidor. 6 ed. Rio de Janeiro: LTC, 2000.

A CBPC - Companhia Brasileira de Produção Científica (CNPJ: 11.221.422/0001-03) detém os direitos materiais desta publicação. Os direitos referem-se à publicação do trabalho em qualquer parte do mundo, incluindo os direitos às renovações, expansões e disseminações da contribuição, bem como outros direitos subsidiários. Todos os trabalhos publicados eletronicamente poderão posteriormente ser publicados em coletâneas impressas sob coordenação da Sustenere Publishing, da Companhia Brasileira de Produção Científica e seus parceiros autorizados. Os (as) autores (as) preservam os direitos autorais, mas não têm permissão para a publicação da contribuição em outro meio, impresso ou digital, em português ou em tradução. 